\title{
Erratum to: Bucillamine-induced yellow nail in Japanese patients with rheumatoid arthritis: two case reports and a review of 36 reported cases
}

Daiki Nakagomi • Kei Ikeda - Hirotoshi Kawashima • Yoshihisa Kobayashi · Akira Suto - Hiroshi Nakajima

Published online: 11 September 2013

(c) Springer-Verlag Berlin Heidelberg 2013

Erratum to: Rheumatol Int (2013) 33:793-797

DOI 10.1007/s00296-011-2241-z

The author would like to correct his first name in the original version of the published article. The correct name should be "Hirotoshi Kawashima."

The online version of the original article can be found under doi:10.1007/s00296-011-2241-z.

D. Nakagomi · K. Ikeda ( $₫) \cdot$ H. Kawashima · Y. Kobayashi ·

A. Suto $\cdot$ H. Nakajima

Department of Allergy and Clinical Immunology,

Chiba University Hospital, Chiba, Japan

e-mail: k.ikeda@faculty.chiba-u.jp 